\title{
Skateboarding and Street Culture
}

lain Borden

Number of words: 6487

Date revised/edited: February 14, 2019

"Skateboarding is not a hobby and it's not a sport. Skateboarding is a way of learning how to redefine the world around you." Ian Mackaye

\section{Introduction}

Skateboarding is often viewed as a form of subculture, one of Dick Hebdige's (1979) social worlds which confront conventional codes, and helps people to identify themselves. In the 1990s, skateboarding was largely cast by both the mainstream press and skaters themselves as oppositional to normative society, with skaters creating an alternative lifestyle of music, clothes, words, magazines and videos. Yet by the 2010s skateboarding has moved inexorably from subculture into the mainstream, where for many riders skateboarding is less the sole determinant and more a pervasive presence through their lives.

In this dispersed culture, avowed skate-centric qualities like independence and autonomy, distrust and cynicism, camaraderie and jocularity, or creativity and resourcefulness often surface in unpredictable combinations. For example, Guan $\mathrm{Mu}$ (2018) who runs the Chinese Kicker Club website, describes himself not as solely a 'skateboarder' but as a 'father, skater, husband, Christian, developer' - a conflation which would have been highly unusual in 1980s and 1990s skate scenes. It is to these complexities and seeming contradictions that we now turn, looking at such characteristics as skateboarding's avowed outsider status, age groups, ethnicity, masculinity and criminality, as well as more recent developments in extended age, gender diversity and attitudes to commerce. As we shall see, all of this is directly connected to skateboarding's inherent street-related performances and credentials.

\section{Freaks and Geeks}

In its most distinctive social world, the kind of street-based skateboarding which came to the fore in the 1990s has separated itself from cosy clubs, regulated schools and organized teams, being more impromptu in organization, independently creative and exploitative of its 'sub-' status. Through riding down suburban roads and downtown spaces, skateboarders are also often disruptive and so unsettle conventional society in an ambiguous yet challenging manner. This was especially the case during the 1990s, when skaters often saw themselves, in Grosso's words 
(2015), as society's 'freaks and geeks', and ever since this period skateboard discourse has consistently characterized skaters as eccentrics, outcasts and rebels.

Furthermore, skateboarding is typically practised by younger adults and teenagers; one 2009 estimate placed ninety-three per cent of US skaters below twenty-four-years-old (Whitley, 2009, p. 87). With this comes the general attitude of youth which in Lefebvre's (1969) words 'revolts against the Fathers', and which among skaters is frequently expressed as a dislike of routinized training and memberships (pp. 106-7). Skateboarders are 'not kids whose dads gave them batting practice out in the front yard,' explained skate magazine Thrasher. 'It's not a fatherson deal' (Gabriel, 1987). So instead of normative institutions like school, family and teams, skaters opt for a sense of personal freedom. The opinions of a rider like Shayne Stadnick are typical, revelling in the fact that in skateboarding, particularly when it takes place in city streets rather than in legitimised skateparks, 'there is no coach to impress or teammates to let down, no rules or regulations' and 'no scheduled times' (Harms \& Smith, 2009, p. 49).

An even more general critique of normative society is also discernible in skateboarding, what Beal (1998) has called a 'symbolic inversion' and a 'daily critique and alternative to mainstream relations' (p. 213). In 1983, the skateboarder and skate journalist Garry Scott Davis (GSD), for example, viewed things like 'baseball, hotdogs, apple pie, weed, beer, pills, needles, alcohol' as just the 'typical hobbies of all the typical people' in America. His conclusion was simple: 'Why be a clone?' Indeed, in their more extreme formulations, such skate subcultural attitudes encompass everything a skater does. 'One way or another,' asserted Skatemaster Tate (Gerry Hurtado), 'skating relates to just about every part of my life' (Grogan \& Arrington, 1987).

\section{Everything in Between}

As many academics have argued, not everything, however, is perfect in skateboarding's cultural garden. Studies of Michigan and Swedish skaters by Yochim (2010) and Hellman (2016) show how some white male skaters imagine themselves as victims and act non-inclusively. Meanwhile skate videos like Powell-Peralta's Ban This (1989), Santa Cruz's Streets on Fire (1989), and Shorty's Guilty (2002) cast skaters as misunderstood criminals, victimized because of their marginal and oppositional status. According to Butz (2012), skaters here erroneously present themselves as major victims, for, however much riders might face anti-skate legislation attitudes in city streets - such as tickets, fines and/or confiscated skateboards for riding in public places, or the installation of metal 'skatestopper' protrusions to hinder riding along rails, ledges and benches - they do not face kinds of pervasive repression or discrimination of many other social groups (pp. 190-7).

Skateboarding culture can be equally reductive in other areas. Leonard (2008) identifies how the Tony Hawk video games ignore poverty, violence and police brutality, and so aestheticize ghettos as 'exotic tourist destinations,' while Brayton (2005) shows how skateboard media regularly depict white-privileged travel 
alongside rebellious cool and supposedly 'black cultural' signifiers like hip-hop, gangsta criminality and virulent sexuality. For street-skaters in particular - who are often shown performing transgressive and dangerous acts such as sliding down long rails or leaping down sets of stairs in office plazas and other downtown spaces Atencio, Beal and Wilson (2009), Beal (1996), Beal, Atencio, Wright and McClain (2016), Beal and Wilson (2004) and Orpana (2015) have all argued that the typically hyper-performing, overtly male and highly individualized body of this kind of steetriding skater aligns neatly with neoliberal patriarchal structures and their focus on risk, masculinist hierarchies and the denigration of women. Consequently, Yochim calls skateboarding a 'corresponding culture' which critiques dominant masculinities (notably 'jock' athletes) without truly challenging the power of the dominant straight and white middle-classes (pp. 4 and 21-3).

Nonetheless, however apparently damning these academic interpretations of skateboarding culture might seem, they are also complicated and to some extent refuted by skateboarding's actual social constitution and attitudes. Additionally, what was true in the 1990s or early 2000s is not necessarily true today, and much skateboarding culture is far from the reactionary bastion which some have perceived.

In particular, skateboarding often transcends class, religion and ethnicity, and skaters have generally come from more varied backgrounds than occurs in traditional sports. Because street skaters often come from diverse locations and neighborhoods to congregrate at specific urban locations - what street skaters call 'skatespots', riders like Jeremy Henderson (1979) welcome a scene with 'all different types of economic groups', Andy Macdonald (2003) describes Massachusetts as a place where rich and poor kids alike formed their local skate crew (p. 36), and Bob Burnquist benefitted from how skateboarding could 'bridge social barriers' with Rio's favelas (Mosberg, 2006). Today, notes Dinces (2011), 'skaters hail from working- and upper-class backgrounds, and everything in between.' Religious categories can also be transcended, as Drissel (2012) demonstrates in Belfast, where skating together at skatespots across the city means that skaters engage in 'collective identity work' and forge non-sectarian relationships.

A wide range of ethnicities are also integrated into skateboarding, which since the mid-1990s has often been seen as a racially mixed world. At first glance, a degree of caution is advisable here. In particular, there are often commercial processes which some are keen to exploit. In the 1980s, pro skater Christian Hosoi - himself of Japanese, Scottish-Irish, French, Chinese and Hawaiian extraction - frequently employed graffiti and gang symbols, and which were quickly taken up by suburban skaters. Even earlier, 1970s Dogtown deck graphics had been derived from Los Angeles Hispanic gang culture, while later companies like Eightball, Grind King and Neighborhood also used gangster references. And for branding purposes this strategy of interconnecting skateboarding, ethnicity, street-level and gang culture has clearly worked. In 2004, Reebok sponsored skater Stevie Williams, who came to fame through his skilled riding at the infamous 'Love Park' location in downtown Philadelphia, and who later formed the DGK (Dirty Ghetto Kids) sub-brand, and by 
All of this could be seen as superficial consumerism in which ethnicity, in bell hooks's (1992) words, is used to 'liven up the dull dish that is mainstream white culture'. Atencio, Beal and Yochim (2013) similarly argue that skateboarding is a predominantly white and male activity, using 'skurban' (skateboarding + urban) racialized images to sell goods and support neoliberalism. They note how one 2009 Nike video advertisement, featuring Mexican-American skater Paul Rodriguez (aka PRod) and accompanied by Ice Cube's 'It Was a Good Day', strips away the suggestions of racial inequality and injustice which are essential components of the original track. Instead, in this shoe ad version, P-Rod freely skates across an idealized Los Angeles playground of multi-ethnic friends, traffic-free roads and acquiescent police. Such representations provide utopian glimpses of multi-ethnicity, but simultaneously privilege individual status, emphasize meritocracy, avoid critiquing real life, and ignore the need for social intervention in complex urban conditions.

Skateboarding's multi-ethnicity could then be viewed as largely a matter of appearances and branding, close to Brayton's 'crossover' culture and 'limited to the consumption of essentialized black culture such as rap and basketball apparel'. Yet, because skateboarding ultimately takes place on real city streets and so involves physical bodies who meet and converse, and is not limited to mediated images, skate ethnic diversity does frequently extend into real friendships. Here it comes closer to Brayton's 'crossing over' with 'direct engagement and communication between people of color and Whites'. 'In skating, there is no segregation really', states Billy Miller (1996), because 'you don't become aware of their skin color. It just doesn't matter.'

This pluralism is particularly true of recent skateboarding, for, while 1970 s skaters often tended to be white surfers, from the 1980s onwards they have been more ethnically varied, such as 1980s pros Hispanic Steve Caballero, JapaneseAmerican Lester Kasai and African-American Steve Steadham, or 1990s professionals like Armando Barajas, Omar Hassan, Lavar McBride, Kien Lieu and Willy Santos. By the mid-1990s, the newly dominant street-skating particularly attracted economically-disadvantaged skaters of colour, as with Keenan Milton and Chico Brenes appearing in Chocolate's Las Nueve Vidas de Paco (1996), while AsianAmericans formed twenty per cent of National Skateboard Association members (Sueyoshi, 2015). Such diversity is now commonly replicated in mass-market representations; by 2015 the Tony Hawk game included two black (Nyjah Huston, Ishod Wair), one Latino (David González) and two female skaters (Letícia Bufoni, Lizzie Armanto) among its headliners.

Outside professional circles similar patterns are discernible. According to Sheldon Thompson, the Brooklyn Museum skatespot in New York changed from a predominantly white location to being for everybody (Detrick, 2001); elsewhere in New York, as shown by White (2015) and Concrete Jungle (Eli Morgan Gesner, 2009), between the 1980s and 2000s Bronx skateboarding went from a punk and 'whiteboy' 
activity to being undertaken by hip-hop-listening black, Dominicans and Puerto Ricans. Indeed, skate ethnic diversification is now a nationwide US trend. In 2007 the New York Times commented on how across the USA 'skateboarding has joined the fraternity of minority street games', and in 2014 some thirty-four per cent of skaters came from non-white backgrounds, roughly equivalent to the thirty-seven per cent of non-whites in the US population (Detrick, 2001).

Unsurprisingly, given this diversity and engagement between skaters on city streets, and where they mutually engage in the transgressive riding of urban elements, there are relatively few racial tensions within skateboarding, and indeed many skaters have fully embraced a varied class and ethnic life. East Coast skater Bryan Ridgeway recalled how his fellow African-Americans 'pretty much all had white, Asian, Hispanic buddies', while Sueyoshi (2015) notes how Asian-Americans have considered the skate community as a place of "racial tolerance where different people could come together and be judged purely for their skating ability'.

\section{Beer and Barneys}

Notwithstanding the increasing presence of female skaters discussed below, masculinity, notes Yochim (2010), is often the predominant identity within skateboarding. One place to locate this masculinity is the long-standing Thrasher skateboarding magazine, which has been especially connected with beer-drinking, hardcore-music, weed-smoking, party-seeking and all round rowdiness; 'I won't conform, I'm a piece of trash, fuck the established' sings Duane Peters in 'Love and Hate' with his punk band The Hunns (Lucero, 2005). This stance is typified by Thrasher's video Beers, Bowls and Barneys (Maigetter, 2004), with twenty-five minutes of on-the-edge riding, body-jarring slams, beer-drinking, hardcore music and raucous revelry, all of which takes place within a diverse urban realm of city streets, urban plazas and abandoned suburban swimming pools.

How do we understand this masculinity? At first sight skateboarding is seemingly constituted as a determinedly heterosexual masculinity, marked by casual aggression, independence and rebellion against the supposedly more normative members of urban society. This is evident not only from Thrasher but in Big Brother magazine of the 1990s and films like Larry Clark's Kids (1995), through to lan Reid's Sex, Hood, Skate and Videotape (2006) and the So What (2016) video by London's With Section, which variously show irrepressible skateboarding energy mixed with a street-based milieu of weed, gangs, nudity, offhand violence and ad hoc DIY terrains. 'All I need is my girl, a chewy spliff, and a peanut butter and jelly sandwich to go along with my daily scorched earth domination', declares an Asphalt (2014) advertisement. 'No fucks given.'

Injuries sustained while skateboarding in the urban realm are integral to this male identity, and act as a means to physically display the rider's commitment to skateboarding on a public stage. 'The bruising of one's body', argues Beal (1992), 'demonstrates a traditional masculine characteristic of risking bodily injury' (p. 167), while most skaters - male and female alike - accept that getting hurt is intrinsic to 
skateboarding. Although skateboarding is less dangerous than boxing, American football, snowboarding, ice hockey and mountain biking, and few skaters actively seek accidents (Clemmit, 2009; Hackenheimer, 2007, p. 33), getting hurting is thus viewed as an essential part of skateboarding, with many skate videos including numerous fails, bails and worse as street-skaters hurl themselves down long rails, over steep steps and across obstructive barriers. Thrasher's 911 Emergency (1995) includes the hospitalization of Ricky Oyola, while its Hall of Meat (1999) details a gory series of collisions and falls; today, YouTube contains innumerable 'Best of' slam edits as skaters fail to conquer their urban terrains. Some skaters like Aaron 'Jaws' Homoki have even gained notorious reputations for launching off buildings and undertaking roof-top moves. One of Homoki's feats includes his 2015 jumping of the infamous twenty-five stair set (around four-and-a-half metres drop and seven metres long) at Lyon's Centre de Congrès. Similarly, Tengu: God of Mischief (Colin Read, 2013) starts with high-level roof-top New York manoeuvres, before Koki Loaiza ollies across the electrified train track of the 145th Street station, while the Skate Near Death 'skate-poem' (2016) shows Roma Alimov grinding a platform edge as a train rushes in and negotiating potentially fatal ledges, rails and bridges.

Another pervasive male representation involves the poses and attitudes struck in advertisements. To cite but one classic example, in a 1988 photograph by Steve Gross for the Alva team, twelve leather-clad 'Alva Boyz' stand against an inner city backdrop of bricks wall and warehouse staircase, staring defiantly at the camera, overtly displaying confrontational aggression and a 'gangster-don't-give-a-shit attitude'. According to Tony Alva, these were party-hard and skate-hard 'road warriors' and 'a total destruction machine' (Alva, 1988; Mortimer, 1997; Eisenhour, 2002), and whose primary identity was therefore formed by their ability to ride and play in the urban realm

\section{Crime Time}

At times, skateboarding's symbolism of gangs and semi-illegal activities has spilled over into drugs, violence and worse; renowned professional skaters who have been convicted over the years have included Jay Adams (imprisoned for drugs possession and assault), Ben Tappas (murder, cocaine smuggling), Tas Pappas (domestic violence, cocaine smuggling), Josh Swindell (second degree murder), Neil Heddings (manslaughter), Christian Hosoi (crystal meth smuggling), Mark 'Gator' Rogowski (rape, murder), Paul Hackett (matricide) and Duane Peters (domestic violence). Skater alcohol and/or drug addiction has also occurred with regularity.

Sometimes such criminality even becomes implicitly condoned. For example, Jay Adams' illegal activities are often dismissed as the minor errors typical of a 'bad boy skateboarder'. Hence while Adams - whose central role in the highly influential Venice Beach skateboard pool-riding scene of the late 1970s was depicted in the award-winning documentary Dogtown and Z-Boys (Stacy Peralta, 2001) indifferently described his involvement in the fatal assault of a mixed-race gay couple - 'Beat up some homos. No big deal. We do that shit all the time' - his own untimely death in 2014 lead to eulogizing obituaries which typically dismissed such 
dark episodes as merely the acts of a 'colourful rebel'. Far rarer have been Keith Hamm's more balanced comments, recognising that Adams was 'at his worst, a felon, junkie, and a racist and homophobic deadbeat dad', and simultaneously 'at his best, a legendary surfer and skateboarder, an honest and sober guy who goes to church on Sundays and sends his kid money each month' (Hamm, 2004, pp. 88-9; Smith, 2014).

Here lies a great contradiction within skateboarding street culture, whose masculinity, as demonstrated to both rival skaters and non-skaters alike, can be at once loud and contemplative, violent and considerate, intolerant and respectful. Indeed, SkateBoarder may have presented 1970s skaters as unruly and rebellious, but its overall message was still of skateboarding as being clean-cut, progressive, professional and hierarchical; extreme behaviour in skateparks and skatespots went unreported and photographs showing under-age skaters drinking beer were left unpublished. Parents featured in 'Skateboard Kings' (BBC, prod. Horace Ové, 1978) similarly praised skateboarding as a healthy outlet encouraging balance, agility and mobility, and it is to these kinds of skateboarding culture which we now turn.

\section{Positive and Loving}

That many skateboarders refute the 'jock' sports masculinity of physical domination, extreme competitiveness and overt sexism is, in part at least, evident from skaters' bodies, for, notes Louison (2011, pp. 18-19), most skaters are not demonstrably muscular but lithe or even scrawny. Tony Hawk, Rodney Mullen, Nyjah Huston, Ben Raybourn, Lizzie Armanto et al don't really look like sports athletes, their leanness offering power and agility that brawn would only hinder. And, of course, younger professionals - such as Ryan Sheckler (aged thirteen on turning pro in 2003), or Tom Schaar (aged twelve when winning gold at the Asia X Games) - have even more boyish physiques. Some renowned skaters even contend with significant medical challenges, including Steve Caballero (scoliosis), Rodney Mullen (femoral anteversion), Italo Romano (amputated legs), Steven 'Lefty' Breeding (no right arm), Auby Taylor (Asperger's), Andrew Reynolds (OCD), Tas Pappas (personality disorder), and Mark Rogowski (manic-depression). Deaf skaters have included Nolder and Brandon White.

If skaters rarely express masculinity through pumped muscularity or overt athleticism, other bodily expressions and forms of outward urban display are nonetheless adopted. Most notable are tattoos - popular designs include Thrasher's Skate and Destroy, Independent's Iron Cross, Santa Cruz's Screaming Hand and Spitfire's Fire Head - which Skinned Alive (Bart Saric, 2004) identifies as connecting skateboarding with punk music, individualism and anti-authoritarianism, but which also allow individuals to side-step avoid stereotypical masculine personas. Hence someone like the small-framed Ben Raybourn sports nerdy Ray Ban spectacles and a few tattoos, while becoming globally renowned for his impulsive riding style. Similar to Raybourn in their individualistic yet non-aggressive character are the vast majority of everyday skaters, as well as professionals like the artistic Mark Gonzales, widely acknowledged as the world's most influential skater, and the 'pathologically non- 
confrontational' Tony Hawk (Hawk, 2000, p. 75). Andy Macdonald, a contemporary of Hawk's, adopted Ghandi's philosophy of non-violence; 'What really takes guts is to keep right on walking, confident in who you are.' Responding to a skater's father worried about illegality, profanities and violence, Macdonald argued that these things are actually more prevalent in other sports, and that skateboarding instead offers a drug-free path to self-fulfilment, financial success and civic-mindedness (Macdonald, 2003, pp. 19, 41-2, 68-70).

Another form of alternative masculinity is to see skateboarding as hardcore in its refusal of bodily abuse, where a more positive direction can be pursued. This was especially evident among 1990s 'straight edge' adherents - including skaters like Bill Danforth, 'zines like Skate Edge and bands like Minor Threat - who abstained from risky sex, illegal substances or meat-eating to focus on the purity of mind and body. According to some critics, straight edge was a white middle-class defence against drug-taking and sexuality, without embracing Moral Majority 'just say no' values (Williams and Copes). But whatever its wider context, in skateboarding straight edge became particularly explicit through aggressively acting bodies, appropriative tactics and general subcultural attitudes. Indeed, some of this is latent in skateboarding generally, as when pro skater and punk rocker Steve Caballero (2007) calls for 'more positive, loving and selfless attitudes' within skateboarding, alongside refraining from cigarettes, alcohol and drugs. In this way, skateboarding provides an escape from drugs as both dangerous physiological abuse and entrapping social and urban milieu; for Bob Burnquist, for example, skateboarding (and veganism) provided a way to break away from his teenage São Paulo indulgences of cocaine and gluesniffing (Browne, 2004, pp. 87-8; Hamm, 2004, pp. 191-4).

Notably, Burnquist also drew upon beliefs in Christian Spiritism and reincarnation, while others who have similarly embraced Christianity include Caballero, Eddie Elguera, Christian Hosoi, Lance Mountain, Rodney Mullen, Tas Pappas, Paul Rodriquez and Jamie Thomas. For Hosoi (2012), conversion came when facing a lengthy prison sentence for drugs smuggling, and after release he became an Outreach Pastor, using his skater reputation as 'a platform to preach the gospel' in Californian urban churches (pp. 225-304). For others, God even actively participates in their skateboarding. 'I pray before dropping in', explains Sierra Fellers. "'God, what do you want me to do?" I know it's going to be big, because you don't do little things' (Baldwin, 2005, p. 37). This part of skateboarding is rarely mentioned - particularly within the Thrasher-centred beer and barneys trope - but is nonetheless a pervasive and long-lasting element within skate culture, even when it is performed in city streets worldwide.

\section{Middle Age Shred}

By no means all skateboarders are youngsters. By 1992 over ninety per cent of the riders at Davis skatepark were aged between eighteen and twenty-five, and when London's city centre House of Vans skatepark opened two decades later, over thirtythree per cent of skaters were over thirty (Owens, 2001; Holden, 2014). In 2014, nineteen per cent of all visitors to the Skate Park of Tampa were over forty, 
compared to just over one per cent a decade earlier (Aviani, 2014). For the US as a whole, in 2014 some twenty-eight per cent of US skaters were over twenty-five, and forty-five per cent over eighteen (TransWorld Business, 2015, p. 8).

Sometimes, of course, even renowned older practitioners are discouraged by the scornful stares of the expert young, or by normalising peer pressures. 'The basic attitude I get,' lamented Stacy Peralta 'is 'You're a professional skateboarder? How old are you?"' (Peralta, 1982). Other difficulties include the diminished capacity to withstand body strains and minor breakages, and scheduling time to accommodate other commitments. Despite this, older skaters are increasingly common, particularly in the skatepark, slalom, freestyle and longboarding genres, but also, for those who have grown up riding at downtown locations, in street-based skateboarding. 'Age has got nothing to with it', reflects Australian Peter Rowe (born 1953). 'I just enjoy doing it' (Mills, 2014).

Older beginners like Neal Unger (born 1954) are also well known for their open attitude. 'My goals for my skateboarding', explains Unger (2013), 'are to research the quietness of my mind and how joyful that is. How old can I get and yet still act young?' Unger's additionally talks about applying lessons from skateboarding into his wider friendships, family and creativity (Unger, 2014). And as this suggests, older skaters are often thoughtful about their interactions with other riders. In particular, as demonstrated by Laurent (2012) and O'Connor (2017), older riders frequently look out for younger kids, including how skate traditions are transferred to these new generations. 'The older skateboarders truly understand this is something to pass down to the little guys', explains Heidi Lemmon, manager of a Venice Beach skatepark. 'A seven-year-old girl got on the ramp, and everyone stepped back. These skateboarders really look out for the little ones' (Cave, 2005).

\section{All Girl Skate Jam}

On the surface at least, skateboarding has largely remained a predominantly male activity, particularly during the 1990s when skate magazines tended to emphasize the transgressive exploits of lone male street skaters riding illicit downtown skatespots in the middle of the night. All-male line-ups dominate skateboarding, with videos like Hot Chocolate (Spike Jonze, Ty Evans and Cory Weincheque, 2004) emphasizing the all-male camaraderie of knuckle-bumps, room-sharing and sweaty mini-van travelling. Such representations reinforce the notion that skateboarders are male, and that the absence of females is unproblematic. Yet there have been many females throughout skateboarding's history. In the early 1960s, surfer Linda Benson had a signature skateboard, while in 1965 Donna Cash, Wendy Bearer, Colleen Boyd and Laura (Laurie) Turner gained television coverage as competitors in the American National Skateboard Championship (Segovia and Heller, 2007, p. 117; Porter, 2014, loc. 63). The same year, Hobie's Patti McGee appeared on Life's cover and the 'What's My Line?' and 'Johnny Carson' television shows; her SkateBoarder interview opened by stating that 'skateboarding is 100 percent just as much for girls as it is for boys' (McGee, 1965). 
A decade later, females constituted some twenty-five per cent of Southern Californian skaters (Pennell, 1978), and many 1970s skate documentaries consequently depicted female skaters, many of them traversing suburban roads, including The Ultimate Flex Machine (1975), Spinn'in Wheels (1975), The Magic Rolling Board (1976), Freewheelin' (1976), Blaze On (1978) and Hot Wheels (1978). During this period women frequently joined established teams, as with Ellen Berryman (Bahne, Logan), Pattie Hoffman (Pepsi, Variflex), Robin Logan (Logan), Peggy Oki (Z-Boys), Ellen O'Neal (G\&S, Free Former, Pepsi), Laura Thornhill (Logan) and Gale Webb (Powerflex). Other notables included Teri Lawrence with a substantial pool-riding section in Blaze On.

Into the 1980s and 1990s and, despite some punk-inspired male hostility, many females persevered and even gained notoriety within the emergent street-skating genre, including Cara-Beth Burnside, Cyndy Pendergast, Debbie McAdoo, Anita Tessensohn, Leaf Trienen and many others in the US, plus Michelle Picktin and Sue Hazel in the UK. Highlights included Tessensohn riding in Powell-Peralta's Public Domain (1988), and Burnside's Thrasher cover (August 1989) and appearance in Hokus Pokus (1989). Towards the end of the 1990s and into the 2000s women's skating emerged even stronger, with Patty Segovia-Krause's inaugural All Girl Skate Jam (AGSJ) drawing competitors from USA and internationally. Burnside became the first female to gain a pro shoe (Vans) and appeared in Hurley's Hallowed Ground (2001) (Porter, 2014, locs. 352, 594-615). Elissa Steamer was a particular tour de force; a street-riding Floridian who joined Toy Machine in 1995 and turned pro in 1998, Steamer was interviewed in Big Brother and TransWorld, appeared in Tony Hawk's Pro Skater game, won X Games titles and scored a Thrasher back cover (Singleton, 1997; Porter, 2014, locs. 373-413; Bootleg, 2002). After her appearances in Toy Machine's Welcome to Hell (1996) and Jump Off a Building (1998), Sidewalk noted that the exclusive 'boys club' of skateboarding had now departed (Gray, 2012).

During the early 2000s, things continued to improve when the X Games and Gravity Games introduced female street and vert skating, Vanessa Torres featured in Elementality (2005) and in 2006 the All Girl Skate Jam joined the Vans Warped Tour to reach fifty cities; by 2009, after pressure from the Actions Sports Alliance, the $X$ Games offered prize parity across genders (Segovia and Heller, 2007, pp. 123, 136; Striler, 2011, p. 258).

The All Girl Skate Jam (AGSJ) has been particularly influential. Founded as an annual event, AGSJ provides a community-oriented atmosphere for 'all ages, all abilities, all girls', and has inspired events like Girl Skate Out (UK), Gallaz Jam (Australia and France) and Ride Like a Girl (Canada) (Porter, 2003, pp. 64-5). As Atencio, Beal and Wilson (2009) report, such events offer women of varied femininity, ability, age, ethnicity, class and sexuality the chance to skate without male intimidation, often using urban skateparks rather than city streets for their events. And they have countered male dominance, particularly in streetskateboarding, as well as helping lead to men's and women's events being given equal weighting in the 2020 Tokyo Olympics. 
But what of everyday female skaters? By 2007, around twenty-six per cent of skaters were female, nearing the thirty to thirty-four per cent range or snowboarding, surfing and mountain biking (Booth, 2007, p. 106). Two years later, Atencio, Beal and Wilson (2009) noted the increasing female participation in skateboarding, snowboarding and surfing, with one industry executive seeing women as a crucial factor in expanding markets. Today, even mainstream women's magazines recommend skateboarding in city streets and other locations as expressive and stylish; 'whether you love surfing pavements, cruising beach promenades or hitting hills,' enthused Marie Claire in 2015, 'skateboarding is all about letting go of your worries and living in the moment' (Redfern, 2015).

Numerous websites and social media also promote female skateboarding, many carrying powerful messages. Since 2002, the Skirtboarders website and documentary Skirtboarders: le Film (Mathilde Pigeon, 2004) have depicted Montreal and Ottawa communities as knowing rejections of male/female binaries; these 'polygendered' Skirtboarders fart, spit and wear t-shirts without bra-straps, while bikinis and painted nails may also appear, and so are fluidly female and/or male, hinting at new subjectivities. Bäckström (2013) recounts how some female Swedish skaters deploy gender manoeuvring, using tomboy or lesbian behaviours to disrupt male dominance, while Kelly, Pomerantz and Currie $(2005 ; 2008)$ have shown how Vancouver women have similarly rejected 'emphasized femininities' and instead appropriated male bravado, male clothing, Goth, hip-hop and punk subcultures; as these 'alternative', non-sexualized and androgynous femininities realise, 'you can't land an ollie properly in heels.'

By the mid-2010s, many female skaters have become ever more comfortable in their skating identities. As Porter (2014, loc. 473) asserts, the sheer number of competent female riders means that 'skateboarding does the talking, and the rest is superfluous.' Cindy Whitehead and Ian Logan's It's Not About Pretty and Julian Bleecker's Hello Skater Girl publications both bear this out, showing skaters in varied city-based terrains, emphasising their style, skill and determination to engage with urban locations rather than fashion, appearance or sexuality.

Today, female skaters are still comparatively less numerous and routinely gain less media coverage than male riders; frustratingly, Vans's Propeller video, for example, does not include Lizzie Armanto, despite her being on the Vans roster. And much skateboarding media, remarks Niki Williams in Underexposed: a Women's Skateboarding Documentary (Amelia Brodka and Brian Lynch, 2013), continues to indicate that 'skateboarding is just for white males who have tattoos.' Nonetheless, in most skateparks females are commonly welcomed as equals, while street-riding women are also becoming more numerous; seventeen-year-old Emma Lindgren notes that, because of the social scene at Bryggeriet and other Malmö urban skatespots, 'it's not like they see me as a girl, more as a skater' (Evans, 2014). And so, concludes Porter (2014, loc. 756 ), it seems like we have perhaps finally arrived the tipping point when skateboarders are no longer distinguished by gender, and 'the novelty of girls skateboarding has begun to wear off.' 


\section{Polycultural Practices}

For some practitioners, skateboarding continues as a totalising lifestyle, which dominates their urban identity and practices. 'Hardcore skateboarders are still there,' asserted Glen Friedman to the New York Times (Cave, 2005). Yet for most skaters skateboarding is undoubtedly a central part of their self-understanding, but without being all-encompassing or insurgent. In 2009, Liu Qing of the Chinese Extreme Sports Association was noting that, where skateboarding had originally promoted teenage rebellion, by now it was simply 'a means for young people to challenge themselves' (Bolin, 2009).

In part this is generational, with skateboarding going beyond 1990s Generation X-ers - 'slackers' disgruntled with commercialization and embracing counter-culture - to include Generation Y-ers, that is those who are born post-1982, affluently 'hooked-up' with merchandise, educated and ethnically diverse, and who embrace teamwork, achievement, modesty and good conduct (Howe and Strauss, 2000, p. 4; Beal and Wilson, 2004). For example, young skaters at Kona skatepark, interviewed by Lorr (2015), viewed skateboarding as a mainstream sport, and expected to be supported by parents and teachers; one fourteen-year-old reckoned that skateboarding was 'not rebellion or resistance' but 'just fun'. Skateboarding here mirrors the path of other urban subcultures, no longer a unique channel of identity, but becoming part of the panoply of available style, consumer and entertainment. By 2015, for many young riders skateboarding, far from being baseball's opposite, was now its natural friend: 'riding your board to a Little League game is not only commonplace, it's a necessity' (Padilla, 2015).

Older skaters, too, engage in these polycultural practices. For example, one San Francisco company incorporates skatepark hire into employee benefits, a Johannesburg bank has constructed an on-site ramp, while the people I currently skate with include an accountant, architect, art dealer, graphic designer, lawyer, police officer, quantity surveyor, realtor and software developer, all of whom integrate their 'respectable' careers with 'alternative' skateboarding sensibilities. 'No one should even be discussing if things are mainstream', concludes Brink (2012). 'Just stop acting like it hasn't happened or that you're cooler or more "legit" because you're pointing it out.' From this perspective, skateboarding is simply another of those lifestyle sports (such as BMX, mountain biking, kiteboarding, parkour, snowboarding, surfing, windsurfing etc.) which, according to Wheaton (2004), emphasize newness, grass-roots participation, lifestyle commitment, adrenalin, individualism and risk.

These changing attitudes are accompanied by new social possibilities, for, according to Giroux (2000), popular culture is a rare 'site for negotiation' where youth can 'produce alternative public spheres and represent their own interests' ( $p$ 13). For example, Sander Hölsgens (2018) has shown how, in Seoul, street- and skatepark-based riding can provide a way to address or compensate for South Korea's over-bearing social strictures and pressures. And such moves to the 
mainstream are not necessarily bad, for skateboarding's increasing integration means that it can simultaneously mount acerbic critiques and formulate collaborative dialogues. As Tony Hawk argues, 'A lot of people feel very strongly that skating shouldn't be shared with the general public. I never felt like that. It's amazing that a kid who chooses to skate now literally has career opportunities' (Jones, 2013).

Taking all of this into consideration, skateboarding street culture is evidently a way to engage with the world in general and city spaces in particular. It is neither wholly rebellious rejection nor fully acquiescent consumerism, but rather a means to cope, to construct meanings and to find pleasure. For older riders, skateboarding sits alongside money, career, relationships, play and travel - bleeding across boundaries, but not dominating. And for younger skaters, it means discovering values, building identities and forming friendships. Skateboarding is typically an intrinsic part of a skater's lifestyle, but not the only determinant, and each skater undertakes their own formulation of these equations.

\section{Notes}

This chapter is partly derived from lain Borden, Skateboarding and the City: a Complete History, (London: Bloomsbury, 2019). Research was made possible by the Architecture Research Fund of the Bartlett School of Architecture, University College London.

\section{References}

Alva (1988). Advertisement, Best of Thrasher, 1(1) (Winter), 11.

Asphalt (2014). Advertisement, Thrasher, 405 (April), 42-3.

Atencio, M., Beal, B. \& Wilson, C. (2009). The Distinction of Risk: Urban Skateboarding, Street Habitus and the Construction of Hierarchical Gender Relations, Qualitative Research in Sport \& Exercise, 1(1), 3-20.

Atencio, M., Beal, B. \& Yochim, E.C. (2013). 'It Ain't Just Black Kids and White Kids': The Representation and Reproduction of Authentic 'Skurban' Masculinities, Sociology of Sport Journal, 30(2), 153-72.

Aviani, V. (2014). Skateboarding From Fad to Profit, Liberty Voice, (15 June). www.guardianlv.com.

Bäckström, A. (2013). Gender Manoeuvring in Swedish Skateboarding, Young, 21(1), 29-53.

Baldwin, S. (2006). Livin It. Nashville: B\&H.

Beal, B. (1992). The Subculture of Skateboarding: Beyond Social Resistance. EdD thesis, University of Northern Colorado. 
Beal, B. (1996). Alternative Masculinity and Its Effects on Gender Relations in the Subculture of Skateboarding, Journal of Sport Behaviour, 19(3), 204-20.

Beal, B. (1998). Symbolic Inversion in the Subculture of Skateboarding, in Duncan, M. Chick, G. \& Aycock, A. (1998) (Eds.). Diversions and Divergences in Fields of Play. (pp. 209-22). Greenwich, Ablex.

Beal, B., Atencio, M., Wright, E.M. \& McClain, Z. (2017). Skateboarding, Community and Urban Politics, International Journal of Sport Policy and Politics, 9(1), 1123.

Beal, B. \& Wilson, C. (2004). 'Chicks Dig Scars': Commercialisation and the Transformations of Skateboarders' Identities', in Wheaton, B. (2004) (Ed.). Understanding Lifestyle Sports. (pp. 31-54). London: Routledge.

Bolin, H. (2009). Skateboarding Out of the Shadows, China Daily, (22 June). www.chinadaily.com.

Booth, D. (2007) (Ed.). Berkshire Encyclopedia of Extreme Sports. Great Barrington, Berkshire.

Bootleg Skateboard Co (2002). Advertisement, Thrasher, 263 (December), back cover.

Brayton, S. (2005). Black-Lash: Revisiting the 'White Negro' through Skateboarding, Sociology of Sport Journal, 22(3), 356-72.

Brink, R. (2012). The Insider Scoop with Rob Brink, Jenkem, (24 January). www.jenkemmag.com.

Browne, D. (2004). Amped. London, Bloomsbury.

Butz, K. (2012). Grinding California. Bielefeld, Transcript Verlag.

Caballero, C. (2007). TransWorld Skateboarding, 25th anniversary issue, 36.

Cave, D. (2005). Dogtown USA, New York Times, (12 June). www.nytimes.com.

Clemmit, M. (2009). Extreme Sports: Are They Too Dangerous?, CQ Researcher Blog, (3 April). www.cqresearcherblog.blogspot.co.uk.

Davis, G. (1983). Steep Slopes, Thrasher, 3(5) (May), 8.

Detrick, B. (2007). Skateboarding Rolls Out the Suburbs, New York Times, (11 November). www.nytimes.com. 
Dinces, S. (2011). 'Flexible Opposition': Skateboarding Subcultures under the Rubric of Late Capitalism, International Journal of the History of Sport, 28(11), 151235 .

Drissel, D. (2012). Skateboarding Spaces of Youth in Belfast, Spaces \& Flows, 2(4), 115-38.

Eisenhour, M. (2002). Alva Posse Chronicles 1985-1989, SkateBoarder, 11(10) (August), 82-7.

Evans, P. (2014) (Dir.). Coping Mechanism.

Gabriel, T. (1987). Rolling Thunder, Rolling Stone, (16-30 July)), 73-6.

Giroux, H. (2000). Stealing Innocence. New York, St. Martin's.

Gray, R. (2012). 'Crashing the Boys Club' - Elissa Steamer interview, Sidewalk, (11 June). www.sidewalkmag.com.

Grogan, D. \& Arrington, C. (1987). He's Not Lean But His Rap is Mean, So the Thrashers Relate to Skatemaster Tate, People Weekly, 27 (8 June), 155-6.

Grosso, J. (2015). Jeff Grosso's Loveletters to Skateboarding - Freaks and Geeks. www.youtube.com/watch? $v=\mathrm{d} 1 \mathrm{M} 3 \mathrm{~d} \times 20-\mathrm{A} 4$.

Hackenheimer, C. (2007). Risk-Taking Behavior of Skateboarders and Traditional Sport Participants in Students Ages 13-16 Years. MSc dissertation, University of Nevada.

Hamm, K.D. (2004). Scarred for Life. San Francisco, Chronicle.

Harms, J. \& Smith, J. (2009) (Eds.). The Skateboarder's Journal. Morro Bay, Morro Skateboard Group.

Hawk, T. \& Mortimer, S. (2000). Hawk: Occupation Skateboarder. London: ReganBooks.

Hebdige, D. (1979), Subculture. London, Methuen.

Hellman, A.A. (2016). Skateboarding is Like Dancing, International Journal of Education Through Art, 12(3), 327-44.

Henderson, J. (1979). Interview, SkateBoarder, 6(2) (September), 35.

Holden, L. (2014). Skate Ramps Buzz with Old City Rollers, The Times, (23 August). www.thetimes.co.uk. 
Hölsgens, S. (2018). A Phenomenology of Skateboarding in Seoul, S. Korea: Experiential and Filmic Observations. PhD thesis, UCL Bartlett School of Architecture.

hooks, b. (1992). Black Looks. Boston, South End Press.

Hosoi, C. \& Ahrens, C. (2012). Hosoi: My Life as a Skateboarder, Junkie, Inmate Pastor. New York: HarperOne.

Howe, N. \& Strauss, W. (2000). Millennials Rising. New York, Vintage Books.

Jones, S. (2013) (Dir.). Off Camera with Sam Jones: Episode 6 with Tony Hawk. www.offcamera.com.

Kelly, D.M., Pomerantz, S. \& Currie, D.H. (2005). Skater Girlhood and Emphasized Femininity, Gender and Education, 17(3), 229-48.

Kelly, D.M., Pomerantz, S. \& Currie, D.H. (2008). 'You Can Break So Many More Rules': the Identity Work and Play of Becoming Skater Girls, in Giardina, M. \& Donnelly, M. (2008) (Eds.). Youth Culture and Sport. (pp. 113-25). Abingdon, Routledge.

Laurent, J. (2012). Le Skateboard. Paris, L'Harmattan.

Lefebvre, H. (1969). The Explosion. New York, Monthly Review.

Leonard, D. (2008). To the White Extreme in the Mainstream, Giardina, M. \& Donnelly, M. (2008) (Eds.). Youth Culture and Sport. (pp. 91-112). Abingdon, Routledge.

Lorr, M.J. (2015). Skateboarding as a Technology of the Collective, in Lombard, K.J. (Ed.). Skateboarding: Subcultures, Sites and Shifts. (pp 139-51). Abingdon, Routledge.

Louison, C. (2011). The Impossible: Rodney Mullen, Ryan Sheckler and the Fantastic History of Skateboarding. Guilford, Lyons.

Lucero, J. (2005) (Dir.). Who Cares: the Duane Peters Story.

Macdonald, A. \& Digeronimo, T.F. (2003). Dropping In with Andy Mac. New York, Simon Pulse.

Maigetter, P. (2004) (Dir.). Beers, Bowls and Barneys.

McGee, P. (1965). Profile: Pat McGee, SkateBoarder, 1(4) (October), 10-13.

Miller, B. (1996). Interview, Heckler. www.heckler.com. 
Mills, T. (2014) (Dir.). Oldog.

Mortimer, B. (1997). Stacy Peralta, TransWorld Skateboarding, 15(11) , 90.

Mosberg, J. (2006) (Dir.). The Reality of Bob Burnquist.

Mu, G. (2017). wwwguanmu.name.

O'Connor, P. (2017). Beyond the Youth Culture: Understanding Middle Aged Skateboarders through Temporal Capital. Lingnan University Staff Publication.

Orpana, S. (2015). Steep Transitions: Spatial-temporal Incorporation, Beasley Skate Park, and Subcultural Politics in the Gentrifying City, in Lombard, K.J. (2015) (Ed.). Skateboarding: Subcultures, Sites and Shifts. (pp. 152-68). Abingdon, Routledge.

Owens, P.E. (2001). Recreation and Restrictions: Community Skateboard Parks in the United States, Urban Geography, 22(8), 782-97.

Padilla, D. (2015). Tyler Saladino's Connection to the Skateboarding World, ESPN, (17 September). www.espn.go.com.

Pennell, P. (1978). Skateboarding. London, GLC Intelligence Unit, London Topics n.24.

Peralta, S. (1982). Interview, Thrasher, 2(5) (May-June). 17.

Porter, N. (2003). Female Skateboarders and their Negotiation of Space and Identity. PhD thesis, Concordia University.

Porter, N. (2014). The History of Women in Skateboarding. eBook/Kindle.

Redfern, C. (2015). 10 Reasons to Get Into Skateboarding As An Adult, Marie Claire, (13 August). www.marieclaire.co.uk.

Segovia, P. \& Heller, R. Skater Girl. Berkeley, Ulysses.

Singleton, C. (1997). Elissa Steamer, Big Brother, 27 (August), np.

Smith, J. (2014). Maybe We Shouldn't Be So Quick to Idolise a Gay-Bashing Skateboarder, Vice, (19 August). www.vice.com.

Striler, A. (2011). X Play Nation. San Diego, Striler Publishing.

Sueyoshi, A. (2015). Skate and Create: Skateboarding, Asian Pacific America, and Masculinity, Amerasia, 41(2), 2-24.

TransWorld Business (2015). The State of Skate. TransWorld report. 
Unger, N. (2014). Neal Unger - 60 Year Old Skateboarder. www.youtube.com/watch?v=IM4FQ FqEhQ.

Unger, N. \& Earhart, M. (2013). Dude Logic. eBook/Kindle.

Wheaton, B. (2004). Introduction, in Wheaton, B. (2004) (Ed.). Understanding Lifestyle Sports. (pp. 1-28). London, Routledge.

White, K. (2015). 'We Out Here': Skateboarding, Segregation and Resistance in the Bronx'. MA thesis, Fordham University.

Whitley, P. (2009). Public Skatepark Development Guide. Portland, Skaters for Public Skateparks.

Williams, J.P \& Copes, H. (2005). How Edge Are You? Constructing Authentic Identities and Subcultural Boundaries in Straightedge Internet Forums, Symbolic Interaction, 28(1), 67-89.

Yochim, E.C, (2010). Skate Life. Ann Arbor, University of Michigan. 